\title{
Transcatheter mitral valve implantation with Tiara bioprosthesis
}

Anson Cheung ${ }^{1}$, MD; Dion Stub ${ }^{1}$, MBBS, PhD; Robert Moss ${ }^{1}$, MD; Robert H. Boone ${ }^{1}$, MD; Jonathon Leipsic ${ }^{1}$, MD; Stefan Verheye ${ }^{3}, \mathrm{MD}, \mathrm{PhD}$; Shmuel Banai ${ }^{2}$, MD; John Webb ${ }^{1 *}$, MD

1. The Centre for Heart Valve Innovation, St Paul's Hospital, Vancouver, Canada; 2. The Tel Aviv Medical Center, Tel Aviv, Israel;

3. ZNA Middelheim Hospital, Antwerp, Belgium

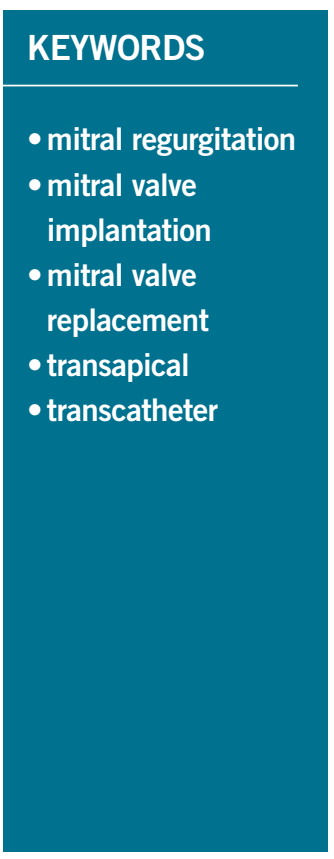

\section{Abstract}

Mitral valve surgery is the gold standard therapy for severe mitral regurgitation, but can be associated with significant morbidity and mortality. Percutaneous mitral leaflet repair has recently been established as a viable alternative to surgery, but many patients are ineligible and repair may not be optimal. Transcatheter mitral valve implantation may be an alternate therapeutic option, particularly for high-risk patients. We outline the initial preclinical and first-in-human experience with the Tiara transapical mitral valve implantation system, highlighting the ease of implantation, proven feasibility and excellent haemodynamic performance.

*Corresponding author: Centre for Heart Valve Innovation, St Paul's Hospital, 1081 Burrard Street, Vancouver, BC, V6Z 1Y6, Canada.E-mailjohn.webb@vch.ca 


\section{Introduction}

Mitral regurgitation (MR) is the most prevalent valvular heart disease, present in over $9 \%$ of patients greater than 75 years of age ${ }^{1}$, and is a major contributor to cardiac morbidity and mortality. Although conventional surgical repair or replacement remains the gold standard treatment for severe MR, it is often deferred because of high surgical risk ${ }^{2}$. Following conventional mitral valve (MV) surgery, octogenarians may have a reported mortality and morbidity rate of $17.0 \%$ and $35.5 \%$, respectively ${ }^{3}$. Transcatheter aortic valve implantation (TAVI) revolutionised the management of valvular aortic stenosis by providing a safe and efficacious alternative to surgical valve replacement in appropriate higher-risk patients $\mathrm{s}^{4-6}$. Similarly, the risk and uncertain benefit of surgical MV repair or replacement in high-risk patients with severe MR has driven the search for new transcatheter MV therapies.

The structure and function of the mitral valve, however, are far more complex than the aortic valve. This complexity poses many challenges in the development of transcatheter mitral therapies: a D-shaped annulus, the lack of a fibrous annular structure, variability of leaflet and subvalvular apparatus anatomy, as well as the proximity of the MV to the left ventricular outflow tract (LVOT), circumflex coronary artery, and coronary sinus ${ }^{7}$.

The Tiara transapical mitral valve implantation system (Neovasc Inc., Richmond, Canada) is a novel, catheter-based technology for the treatment of severe MR. We provide an overview of the Tiara device, preclinical studies and early experience in high-risk patients with MR.

\section{Tiara system}

The Tiara valve is a self-expanding bioprosthesis with cross-linked bovine pericardial tissue leaflets mounted inside a metal alloy frame (Figure 1). It is implanted using a transapical approach. The valve is anatomically shaped to fit the asymmetric and D-shaped mitral annulus. The atrial portion of the Tiara is designed to facilitate seating of the prosthesis onto the atrial portion of the MV annulus. Ventricular anchoring structures are designed to secure the Tiara onto the fibrous trigones and posterior shelf of the annulus. These features firmly secure the Tiara preventing migration, minimising paravalvular leakage (PVL), LVOT obstruction and coronary vessels encroachment. The valve is loaded into a $32 \mathrm{Fr}$ delivery device just prior to the procedure (Figure 2). The delivery device

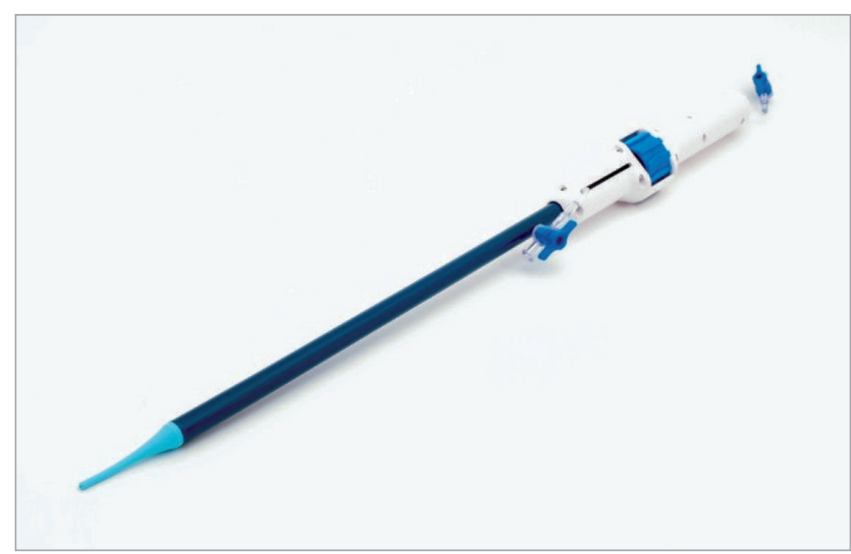

Figure 2. The Tiara transapical delivery system.

comprises a self-dilating tip with a turn knob mechanism and is designed to enter the $\mathrm{LV}$ apex directly without a delivery introducer sheath. Resheathing, repositioning and retrieval of the prosthesis are possible until the final stage of the deployment. The Tiara valve may be used for both functional and degenerative mitral regurgitation. Relative anatomical exclusions include very large annular dimensions and severe mitral and subvalvular calcification.

\section{Preclinical trials}

Preclinical assessment of the safety and feasibility of the Tiara valve, including an acute swine model, chronic ovine model and human cadaveric testing, has been extremely encouraging ${ }^{8,9}$. The acute animal model tested several implantation techniques, with minor modifications and alterations in the design of the prosthesis frame and delivery system. Healthy domestic swine were used. In the acute animal model, Tiara valves were successfully implanted in 29 of $36(81 \%)$ swine with fluoroscopic and three-dimensional (3D) transoesophageal (TEE) guidance. Implantation was unsuccessful in seven animals because of improper positioning of the valve $(n=3)$, failure of the valve anchors $(n=2)$, and ventricular fibrillation $(\mathrm{n}=2)$. None of the valves migrated or embolised after implantation. Significant paravalvular leak was seen only in cases either of MV annulus-prosthesis mismatch or of failed implantation. There was a steady increase in the rate of successful implantation as the series progressed, with the final 12 animals all undergoing successful and uneventful implantation ${ }^{8}$.
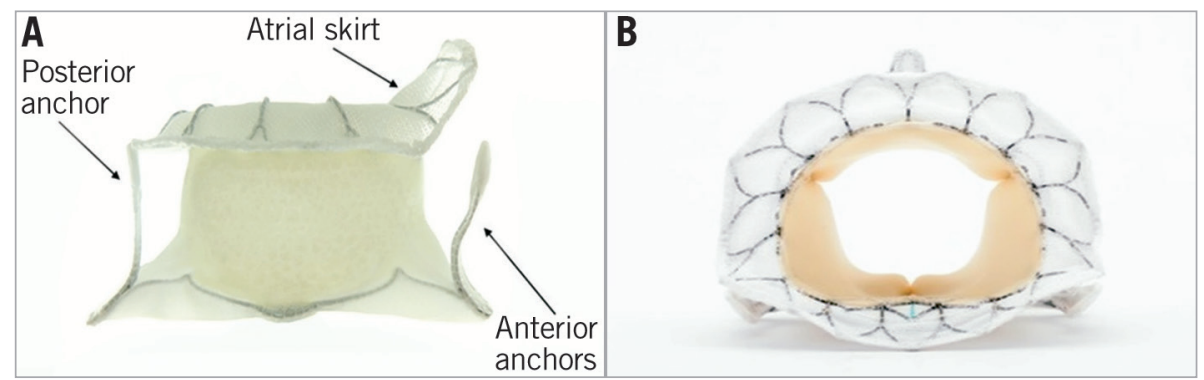

Figure 1. The Tiara transcatheter mitral valve prosthesis. 
A normal ovine animal model was used for longer-term evaluation of the device ${ }^{9}$. Seven animals were evaluated for 150 days after Tiara implantation. All animals had successful procedures and demonstrated clinically stable haemodynamics, maintenance of sinus rhythm and normal behaviour throughout follow-up. Echocardiographic assessment highlighted well-positioned Tiara valves, with excellent leaflet motion and coaptation. Six (86\%) of the animals had mild or moderate PVL. The relatively high rate of PVL observed in the model has been attributed to the fact that only one size of the Tiara valve was available, making size mismatch between the native annulus and prosthetic device unavoidable ${ }^{7}$. In situ cardioscopy showed that the metal struts were homogeneously covered with fibrous tissue, along both the atrial and ventricular struts, indicative of appropriate healing. The pericardial leaflets were intact without tears, perforations or calcifications".

A total of 31 human cadaveric hearts were also studied, in a combination of normal hearts $(n=2)$, hearts with dilated cardiomyopathy $(n=9)$ and hearts with mitral regurgitation $(n=20)$. Implantation of the Tiara prosthesis showed appropriate geometric positioning with full circumferential coverage of the atrial aspect of the mitral annulus and good apposition and location of the ventricular anchoring system ${ }^{9}$.

\section{Early clinical experience}

The first two cases of human Tiara valve implantation were performed in January and February 2014 at St. Paul's Hospital, Vancouver, British Columbia, Canada ${ }^{10}$. Both patients had severe ischaemic cardiomyopathy with a left ventricular ejection fraction of $20-30 \%$, severe functional MR and significant comorbidities (Table 1). The patients were assessed by three cardiologists, and two independent cardiac surgeons deemed with a consensus that the risk with conventional mitral valve surgery was prohibitive. Cardiac multislice computed tomography imaging was performed to delineate mitral valve structures, allow accurate measurement of cardiac dimensions and facilitate preoperative planning of fluoroscopic implant angles. Permission to proceed with transcatheter mitral valve replacement using the Tiara system was granted by the Health Canada Special Access Program.

The procedures were performed in a hybrid operating theatre under general anaesthesia with endotracheal intubation. Invasive systemic arterial and pulmonary arterial monitoring was initiated. Implantations were performed by a multidisciplinary team including a cardiac surgeon and interventional cardiologist, and guided by simultaneous TEE and high-definition fluoroscopy. Patients were positioned supine. Using jugular access the coronary sinus was cannulated with a radiopaque 0.035 inch wire to facilitate fluoroscopic identification of the mitral annular plane. A $4 \mathrm{~cm}$ mini anterior thoracotomy was performed to access the LV apex with the placement of two octagonal pledgeted sutures securing the LV apex. Systemic heparinisation was initiated to achieve an activated clotting time greater than 300 seconds. Needle puncture of the LV apex was performed, followed by the introduction of a 0.035 inch $\mathrm{J}$ wire across the mitral valve and into the left atrium under TEE and fluoroscopic
Table 1. Baseline clinical parameters.

\begin{tabular}{|c|c|c|}
\hline Clinical characteristics & Patient 1 & Patient 2 \\
\hline Age & 73 years & 61 years \\
\hline Comorbidities & $\begin{array}{l}\text { CAD, CRT, HTN, Type II DM, } \\
\text { CKD, COPD }\end{array}$ & $\begin{array}{l}\text { CAD, AF, HTN, COPD, } \\
\text { chronic liver disease }\end{array}$ \\
\hline Mechanism of MR & Functional MR & Functional MR \\
\hline STS risk score & $47.7 \%$ & $4.5 \%$ \\
\hline NYHA functional Class & 4 & 3 \\
\hline GFR $\mathrm{ml} / \mathrm{min}$ & 22 (intermittent dialysis) & 80 \\
\hline
\end{tabular}

guidance. A 7 Fr sheath was then utilised to introduce a 0.035 inch Amplatz Extra-Stiff wire (Cook Medical, Bloomington, IN, USA). The Tiara delivery system was inserted into the LV directly and across the MV into the mid LA (Figure 3A and Figure 3B). This was followed by the release of the atrial portion of the Tiara (Figure $4 \mathrm{~A}$ and Figure 4B). Orientation of the flat portion of the D-shaped Tiara to the LVOT, coaxiality and alignment were confirmed with 3D TEE in the mid left atrium (Figure 5). After full deployment of the atrial skirt, the Tiara valve was rotated until the flat portion of the D-shaped frame corresponded with the LVOT. Seating of the Tiara valve onto the atrial annulus was achieved by gentle traction towards the LV. Rapid ventricular pacing at a rate of 180 beats per minute was initiated and the ventricular anchoring mechanism was released with capture of the anterior and posterior native mitral leaflets (Figure 5).

In both cases the Tiara device was rapidly and easily deployed on the first attempt. TEE confirmed secure seating of the prosthesis with normal valvular function, trivial PVL and a transvalvular gradient of 2-3 mmHg. LV angiography confirmed the absence of significant $\mathrm{MR}$ and invasive pressure measurement confirmed an unobstructed LVOT. Selective left coronary injection confirmed a patent and uncompressed circumflex artery. Both patients were haemodynamically stable throughout the procedure. An increase in systemic pressure and a reduction of pulmonary pressure were evident post-implant. There were no LV apical access issues. Neither patient required blood transfusions. Patients were extubated in the operating theatre and transferred in stable condition to the post-surgical intensive care unit.

Both patients made good recoveries and repeat transthoracic echocardiograms at four weeks demonstrated normal valve 


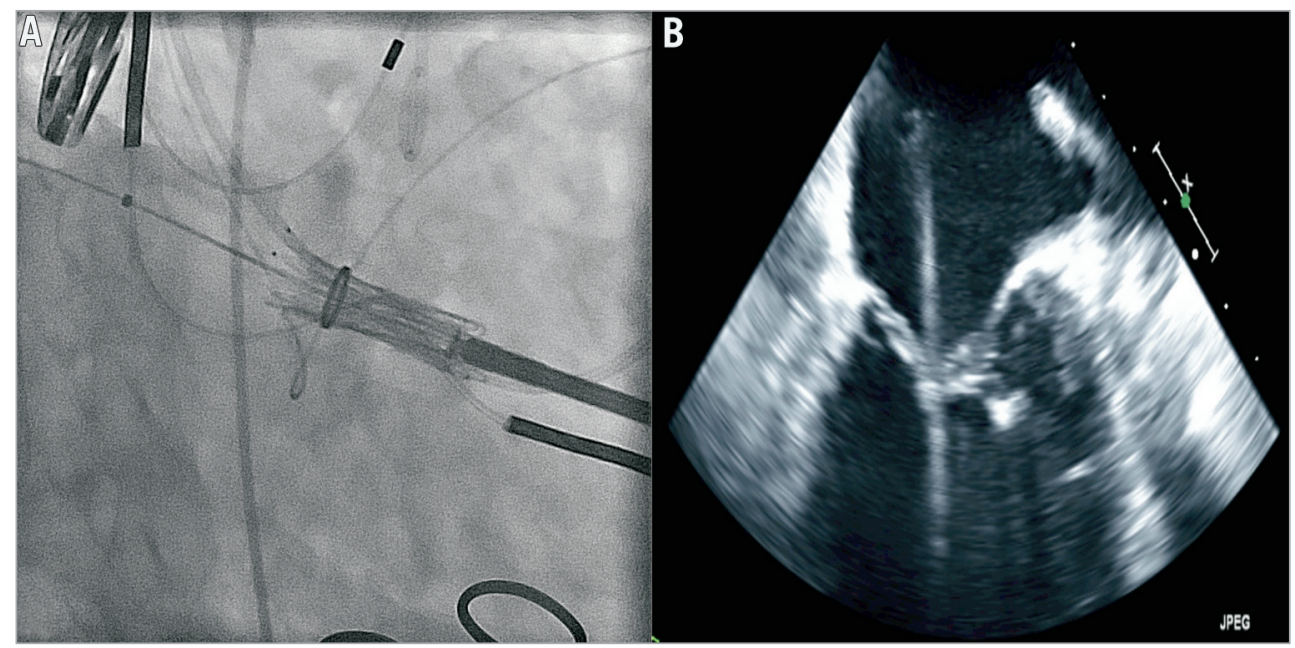

Figure 3. Positioning of the Tiara system across the mitral valve into the left atrium.

function, with trivial PVL in the initial patient and no PVL in the second patient. Transvalvular gradient remained low at 2 and $3 \mathrm{mmHg}$ respectively, with no left ventricular outflow tract obstruction. The first patient, however, had persistent symptoms related to congestive heart failure and chronic renal failure leading to death 69 days post-procedure. The second patient remains well at five months, with a significant improvement in dyspnoea and improvement in functional status from NYHA IV to NYHA II and BNP falling from $833 \mathrm{ng} / \mathrm{L}$ to $482 \mathrm{ng} / \mathrm{L}$.

\section{Conclusions}

There remains a significant unmet clinical need in the management of MR, particularly in high-risk patients who may not be suitable candidates for open surgery or percutaneous leaflet repair. The Tiara is a catheter-based mitral implantation system specifically designed to treat mitral regurgitation. Transapical access offers clear advantages in terms of ease of access to the mitral valve and controlled device delivery, with the clinical caveats common to all apical transcatheter interventions. Implantation was relatively easily accomplished and uncomplicated. The Tiara valve has specific features that accommodate the complex structures of the mitral valve apparatus, preventing migration, and sealing paravalvular leaks. This very early experience suggests the adaptability of the Tiara device to the mitral valve apparatus with stable positioning and absence of paravalvular leak or LVOT obstruction, paving the way for wider clinical experience and future trials.

\section{Conflict of interest statement}

A. Cheung and S. Banai are consultants for Neovasc Inc. The other authors have no conflicts of interest to declare.

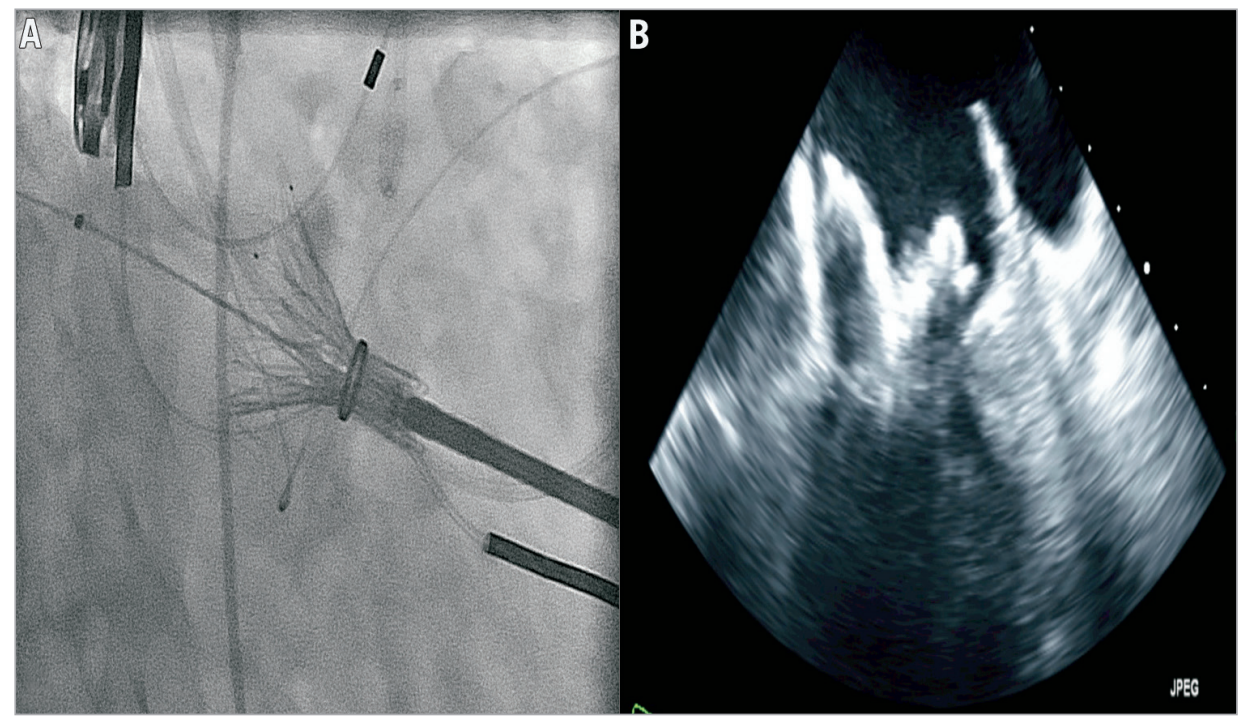

Figure 4. Deployment of the atrial portion of the Tiara bioprosthesis in the left atrium. 


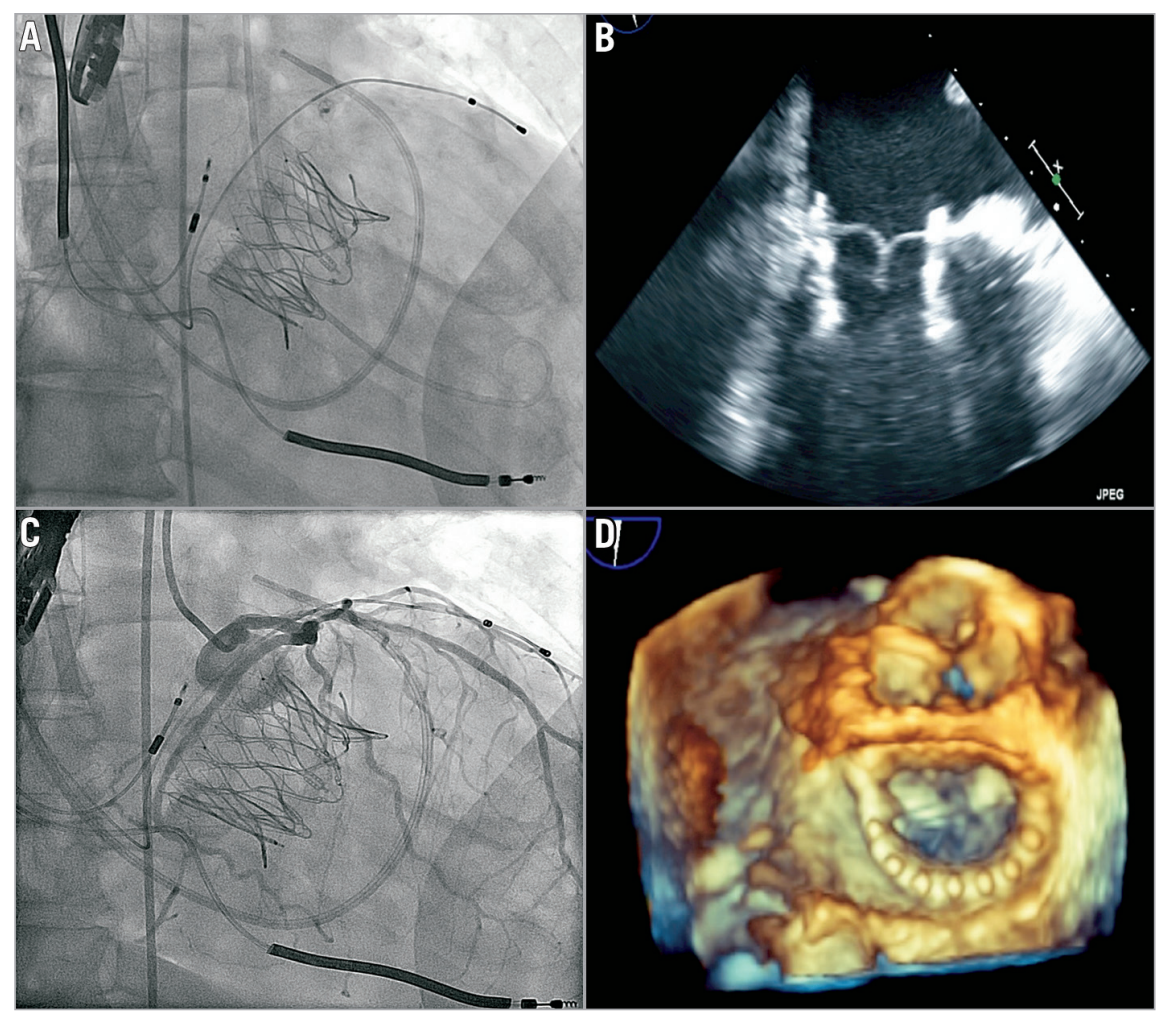

Figure 5. Tiara valve deployed. A, B) Full deployment and release from the delivery catheter. C) Coronary angiogram showed a patent and uncompressed circumflex artery. D) Transoesophageal echocardiography documented a well-seated Tiara bioprosthesis.

\section{References}

1. Nkomo VT, Gardin JM, Skelton TN, Gottdiener JS, Scott CG, Enriquez-Sarano M. Burden of valvular heart diseases: a population-based study. Lancet. 2006;368:1005-11.

2. Enriquez-Sarano M, Akins CW, Vahanian A. Mitral regurgitation. Lancet. 2009;373:1382-94.

3. Mehta RH, Eagle KA, Coombs LP, Peterson ED, Edwards FH, Pagani FD, Deeb GM, Bolling SF, Prager RL; Society of Thoracic Surgeons National Cardiac Registry. Influence of age on outcomes in patients undergoing mitral valve replacement. Ann Thorac Surg. 2002;74:1459-67.

4. Makkar RR, Fontana GP, Jilaihawi H, Kapadia S, Pichard AD, Douglas PS, Thourani VH, Babaliaros VC, Webb JG, Herrmann HC, Bavaria JE, Kodali S, Brown DL, Bowers B, Dewey TM, Svensson LG, Tuzcu M, Moses JW, Williams MR, Siegel RJ, Akin JJ, Anderson WN, Pocock S, Smith CR, Leon MB; PARTNER Trial Investigators. Transcatheter aortic-valve replacement for inoperable severe aortic stenosis. N Engl J Med. 2012;366: 1696-704.

5. Kodali SK, Williams MR, Smith CR, Svensson LG, Webb JG, Makkar RR, Fontana GP, Dewey TM, Thourani VH, Pichard AD, Fischbein M, Szeto WY, Lim S, Greason KL, Teirstein PS, Malaisrie SC, Douglas PS, Hahn RT, Whisenant B, Zajarias A, Wang D, Akin JJ, Anderson WN, Leon MB; PARTNER Trial Investigators. Two-year outcomes after transcatheter or surgical aortic-valve replacement. $N$ Engl J Med. 2012;366:1686-95.
6. Rodes-Cabau J, Webb JG, Cheung A, Ye J, Dumont E, Osten M, Feindel CM, Natarajan MK, Velianou JL, Martucci G, DeVarennes B, Chisholm R, Peterson M, Thompson CR, Wood D, Toggweiler S, Gurvitch R, Lichtenstein SV, Doyle D, DeLarochellière R, Teoh $\mathrm{K}$, Chu V, Bainey $\mathrm{K}$, Lachapelle $\mathrm{K}$, Cheema A, Latter D, Dumesnil JG, Pibarot P, Horlick E. Long-term outcomes after transcatheter aortic valve implantation: insights on prognostic factors and valve durability from the Canadian multicenter experience. J Am Coll Cardiol. 2012;60:1864-75.

7. De Backer O, Piazza N, Banai S, Lutter G, Maisano F, Herrmann HC, Franzen OW, Søndergaard L. Percutaneous transcatheter mitral valve replacement: an overview of devices in preclinical and early clinical evaluation. Circ Cardiovasc Interv. 2014;7:400-9.

8. Banai S, Jolicoeur EM, Schwartz M, Garceau P, Biner S, Tanguay JF, Cartier R, Verheye S, White CJ, Edelman E. Tiara: a novel catheter-based mitral valve bioprosthesis: initial experiments and short-term pre-clinical results. J Am Coll Cardiol. 2012;60:1430-1.

9. Banai S, Verheye S, Cheung A, Schwartz M, Marko A, Lane R, Jolicoeur EM, Garceau P, Biner S, Tanguay JF, Edelman ER, White CJ. Transapical mitral implantation of the Tiara bioprosthesis: pre-clinical results. JACC Cardiovasc Interv. 2014;7:154-62.

10. Cheung A, Webb J, Moss R, Boone R, Ree R, Leipsic J, Verheye S, Banai S. First successful transapical transcatheter mitral valve implantation for mitral regurgitation. J Am Coll Cardiol. 2014 (in press). 